\title{
Employing GIS towards shaping a smart and sustainable future: a brief policy survey of global and Taiwan's efforts
}

\author{
Chih-Wei Chen ${ }^{\mathrm{a}, \mathrm{b}, \mathrm{d}, \mathrm{d}, \mathrm{h}}$, Ching-Yi Lin ${ }^{\mathrm{c}, \mathrm{g}}$, Chine-hung Tungf ${ }^{\mathrm{f}}$, Hsiung-Ming Liao ${ }^{\mathrm{e}}$, Jr-Jie Jang, \\ Kun-Chi Lai ${ }^{\mathrm{c}, \mathrm{d}}$, Meng-Ying Li ${ }^{\mathrm{c}, \mathrm{d}}$, Yin-Ling Huang ${ }^{\mathrm{c}, \mathrm{d}, *}$ \\ ${ }^{a}$ Royal Geographical Society (with IBG). Chih-Wei Chen, chihwei.chen@udm.global \\ ${ }^{b}$ National Council for Sustainable Development. Chih-Wei Chen, chihwei.chen@udm.global \\ c Institute of Urban Diversity and Mobility. Chih-Wei Chen, chihwei.chen@udm.global, Ching-Yi Lin, cshy114@csh.org.tw, Kun-Chi \\ Lai, east0122@tgic.org.tw, Meng-YingLi, mngyng@ttic.org.tw, Yin-Ling Huang,babbie717@tgic.org.tw \\ d Taiwan Geographic Information System Center (TGIC). Chih-Wei Chen, chihwei.chen@udm.global, Kun-Chi Lai, \\ east0122@tgic.org.tw,Meng-YingLi,mngyng@tgic.org.tw, Yin-Ling Huang,babbie717@tgic.org.tw \\ ${ }^{e}$ Academia Sinica. Hsiung-Ming Liao, veevee@gate.sinica.edu.tw,Jr-Jie Jang,roger@gate.sinica.edu.tw \\ f National Chung-Hsing University. Chine-Hung Tung, ct176@columbia.edu \\ g Chung Shan Medical University.Ching-YiLin, cshy114@csh.org.tw \\ ${ }^{h}$ University College London. Chih-Wei Chen, chihwei.chen@udm.global \\ * Corresponding author
}

\begin{abstract}
Since UN announced 17 SDGs in 2015, many countries around the world have been endeavouring to promote SDGs towards building a sustainable future. Given the disparity of the regional development, national government is suggested to establish localised sustainable vision. Drawing on UN SDGs with targets and corresponding indicators, meanwhile considering local circumstances and sustainable vision, government further seeks to establish localised SDGs with related targets and indicators. Meanwhile, under the digital era, digital technologies have been extensively employed as the smart tool in many fields nowadays, and Geographic Information System (GIS) has been developed as the platform to visualise the SDGs progress in UN and many countries. On the above basis, this paper further demonstrates Taiwan's efforts to establish localised SDGs, and develop National Geographic Information System (NGIS) to implement the sustainable development in Taiwan, monitor the SDGs progress, and provide feedback to policymakers to further make strategic policies in a top-down approach, meanwhile develop Community Geographic Information System (CGIS) to encourage stakeholders and citizens to harness the concept of CGIS to proactively create and tell their own stories and promote Regional Revitalisation policy in a bottom-up approach. Moreover, GIS could not function well without appropriate data management including massive data and open data policy, well-built digital infrastructure, as well as the selected "right data" and cyber security. Hence, with appropriate data management, GIS as a smart tool could facilitate the promotion and implementation of SDGs in an intuitive manner towards shaping a smart and sustainable future.
\end{abstract}

Keywords: SDGs, Localisation, NGIS, CGIS, Multi-Data

\section{Introduction}

Contemporary human society is facing severe challenges such as climate change, rapid urbanisation, ageing society, urban decay, and digitisation etc., hence United Nations announced 17 SDGs in 2015 and advocated countries, stakeholders and individuals around the world to endeavour together to address these issues. Although the UN SDGs are the shared value around the world, given the disparity of the regional development, different countries have either prioritised specific SDGs considering local circumstances or established the localised SDGs in terms of vision and values. Those leading countries in sustainable development such as Switzerland, Japan, and Singapore have already fulfilled many of UN SDGs (e.g., SDG1 No Poverty, SDG2 Zero Hunger), hence the government of these countries are contributing more efforts to the areas that are still requiring further efforts by prioritising localised sustainable vision, targets, and corresponding indicators (United Nations, 2018a; United Nations, 2018b; SDGs Promotion Headquarters, 2017).

Alternatively, the occuring of the fourth industrial revolution - digital revolution - has been increasingly altering the human life due to the massive employment of digital technologies, together with other technologies such as data science technologies as well as information and communication technologies, which has also impacted the traditional "top-down" governance approach (World Economic Forum, 2019). Hence, digital technologies are involved in the city planning and governance through a completely new "Mindset" to build e-governance, smart city etc., unfolding a brand-new world imagination, where apart from traditional "top-down" approach, a "bottom-up" approach is also implemented to encourage dynamic public participation and interactions among different sectors in the urban planning and development process, allowing information to be transferred accurately and 
swiftly (Miao, Chen, \& Phelps, 2018). United Nations published E-Government Survey 2018, which elaborated how the e-government could support transformation towards sustainable and resilient societies (United Nations, 2018c). Among all the technologies in digital era, GIS containing geospatial data that provides information from both spatial and time perspectives through data science technologies (e.g., data visualisation) and other technologies is employed as the fundamental carrier to efficiently promote the e-governance and smart city etc., develop the Decision Support System (DSS), address the contemporary challenges, and further achieve the sustainable development goals.

Drawing on UN SDGs and global cases, Taiwan Govt. has investigated and reflected the national and local circumstances to further draft Taiwan's 18 SDGs (Executive Yuan, 2017a). Moreover, following the digitisation and relying on GIS, Taiwan Govt. has been developing the National Geographic Information System (NGIS) for over 20 years, as well as recently proposed and developed the concept of Community Geographic Information System (CGIS), which formed the NGISCGIS framework that allows interactions and communications among government, stakeholders, and citizens from both top-down and bottom-up approaches to facilitate the implementation of national policies, egovernance, smart city etc. towards shaping a sustainable future for Taiwan.

This paper aims to demonstrate the employment of GIS towards shaping a smart and sustainable future via a brief policy survey including global and Taiwan's efforts. Firstly, the global cases are reviewed which use GIS to facilitate the international and national endeavours towards a sustainable future, followed by Taiwan's efforts on localised SDGs via NGIS-CGIS framework. Moreover, in order to ensure the smooth promotion and implementation of sustainable development through NGIS-CGIS framework, open data, digital infrastructure, and data security are discussed to create a robust and healthy environment. On the above basis, GIS as a smart tool could contribute to the sustainable development of Taiwan.

\section{Towards sustainable future: Global efforts}

Facing severe challenges of contemporary human world, United Nations officially launched 17 SDGs with 169 targets, which depicted a blueprint in peace and prosperity now and into the future for all people and the planet, as well as called for urgent actions by global partnership of developed and developing countries to endeavour together towards the achievement of 17 SDGs by 2030. As a follow-up, UN General Assembly further adopted a robust framework of SDG indicators (containing 232 indicators) to assist in ensuring the accountability of statistical data, measuring the progress of sustainable development, and providing feedback to policymakers (United Nations, 2017).

Echoing the UN SDGs, many countries have been seeking to incorporate SDGs as an essential part of their national policy. However, due to the disparity of the regional development in terms of social, economic, and environmental issues, different countries and regions have enormous differences while setting up the priorities of their national strategies, which make it unreliable for all to blindly follow the same SDGs priorities and stay in the same progress. In response to such dilemma, the SDGs Cities Guide that was jointly developed by Sustainable Development Solutions Network (SDSN) and German government emerged to address the issue, which provided a guideline for cities to initiate the implementation of SDGs in cities and human settlements at the local level (SDSN \& German Cooperation, 2016).

Those countries advanced in sustainable development such as Switzerland, Japan, and Singapore etc. all have established their national SDGs by taking local conditions into account. According to Switzerland Voluntary National Review 2016 and 2018 (United Nations, 2016; United Nations, 2018a), Switzerland as a driving force towards 2030 Agenda is already at the forefront of achieving SDGs and has accomplished many targets. Under such circumstances, a comprehensive baseline assessment regarding the implementation status of SDGs was commissioned by Switzerland Federal Council to analyse the gaps towards 2030 Agenda. It was reported that Switzerland was already free from extreme poverty (target 1.1) and hunger (target 2.1), as well as enjoying free education with excellent quality; hence, Switzerland followed the spirit of UN SDGs and developed the Sustainable Development Strategy, which prioritised 9 thematic areas for sustainable development in Switzerland (in Table 1.).

\begin{tabular}{|c|c|}
\hline Thematic areas & $\begin{array}{l}\text { Corresponding UN } \\
\text { SDGs }\end{array}$ \\
\hline Consumption and production & SDG12 \\
\hline $\begin{array}{l}\text { Urban development, mobility } \\
\text { and infrastructure }\end{array}$ & SDGs 9 and 11 \\
\hline Energy and climate & SDGs 7 and 13 \\
\hline Natural resources & SDGs 2, 6, 14, and 15 \\
\hline Economic and financial system & SDGs $8,10,16$, and 17 \\
\hline $\begin{array}{l}\text { Education, research and } \\
\text { innovation }\end{array}$ & SDG 4 \\
\hline Social security & SDGs 1 and 16 \\
\hline $\begin{array}{l}\text { Social cohesion and gender } \\
\text { equality }\end{array}$ & SDGs 5, 10, and 16 \\
\hline Health & SDG 3 \\
\hline
\end{tabular}

Table 1. Nine thematic areas for sustainable development in Switzerland. Source: SDGs Knowledge Platform (United Nations, 2016).

Regarding another leading country in sustainable development, according to Japan Voluntary National Review 2017 (SDGs Promotion Headquarters, 2017), Japan followed the SDGs Cities Guide to review the status of SDGs, especially those with lower scores. On the basis of the review, Japan further endeavoured to promote the implementation of the 2030 Agenda by adopting the SDGs Implementation Guiding Principles as the national strategy (SDGs Promotion Headquarters, 2016); as a following up, 
the Guiding Principles further identified Japan’s 8 priority areas that are categorised into "5Ps" (People, Prosperity, Planet, Peace, Partnership) relating to SDGs (in Table 2.) and targets with corresponding indicators (SDGs Promotion Headquarters, 2017).

\begin{tabular}{|c|c|}
\hline $5 \mathrm{Ps}$ & 8 SDGs priority areas \\
\hline People & $\begin{array}{l}\text { 1. Empowerment of All People } \\
\text { 2. Achievement of Good Health and } \\
\text { Longevity }\end{array}$ \\
\hline Prosperity & $\begin{array}{l}\text { 3. Creating Growth Market, } \\
\text { Revitalisation of Rural Areas, and } \\
\text { Promoting Technological Innovation } \\
\text { 4. Sustainable and Resilient Land Use, } \\
\text { Promoting Quality Infrastructure }\end{array}$ \\
\hline Planet & $\begin{array}{l}\text { 5. Energy Conservation, Renewable } \\
\text { Energy, Climate } \\
\text { Countermeasures, and } \\
\text { Material-Cycle Society }\end{array}$ \\
\hline & $\begin{array}{l}\text { 6. Conservation of Environment, } \\
\text { including Biodiversity, Forests, and } \\
\text { Oceans }\end{array}$ \\
\hline Peace & $\begin{array}{l}\text { 7. Achieving Peaceful, Safe and Secure } \\
\text { Societies }\end{array}$ \\
\hline Partnership & $\begin{array}{l}\text { 8. Strengthening the Means and } \\
\text { Frameworks of the Implementation of } \\
\text { the SDGs }\end{array}$ \\
\hline
\end{tabular}

Table 2. "5Ps" upheld in the 2030 Agenda and Japan's 8 priority areas. Resource: the SDGs Implementation Guiding Principles. (SDGs Promotion Headquarters, 2016).

Following the SDGs (with targets and indicators) launched by UN and local authorities, different digital tools (e.g., SDG dashboard, Urban Data Platform, and CitySDK) have been further developed to measure the progress of each country as well as indicate the goal that requires particular attention and faster progress.

United Nations, the USA, the UK and other countries apply SDG dashboard (Figure 1.), which relies on the unified data platform to perform the visualised analysis and monitor on the environmental requirements and economic potentials in the future, as well as provide feedback on the progress of data collection and compile. Moreover, the USA and the UK also released the open source of National Reporting Platform (NRP) that was used to build the dashboard on Github, which could reduce the difficulty to connect between different platforms (SDSN, 2018; US Govt., n.d.; UK Github, n.d.).

Urban Data Platform, jointly initiated by the Joint Research Centre (JRC) and the Directorate General for Regional and Urban Policy (DG REGIO) of the European Commission, provides a platform to visualise the data and information on the basis of the European cities and surrounding regions (JRC \& DG REGIO, n.d.). For example, Figure 2 presents the green infrastructure per capita in European countries from 2010 to 2040, which is an indicator for UN SDG11 Sustainable Cities and Communities as well as allows people to intuitively observe the green infrastructure per capita in different EU countries along with the changing decades simultaneously.

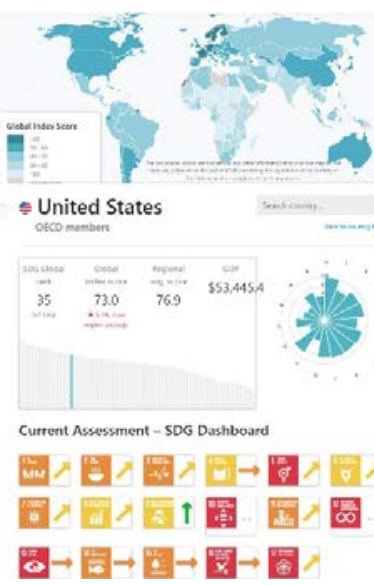

(a) United States

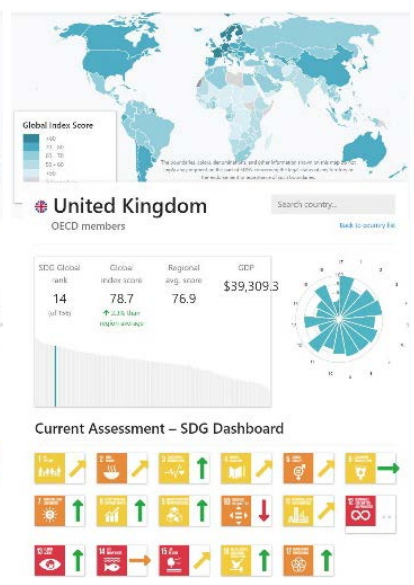

(b) United Kindom
Figure 1. SDG dashboard: (a) United States; (b) United Kingdom. Source: SDG Index and Dashboards Report 2018 (SDSN, 2018).

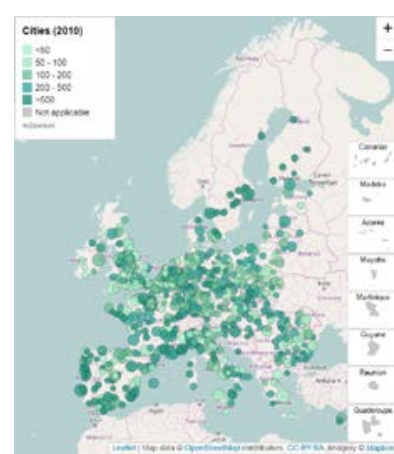

(a) 2010

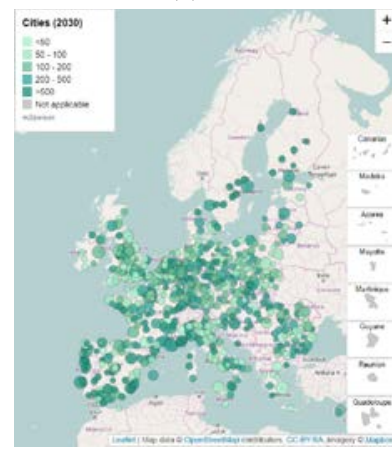

(c) 2030

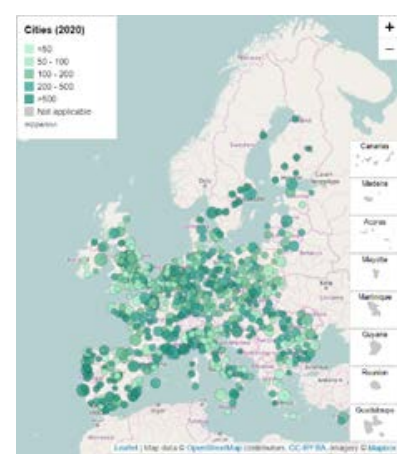

(b) 2020

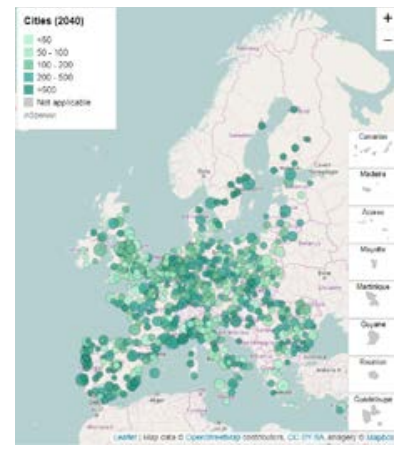

(d) 2040
Figure 2. Green Infrastructure per Capita in European countries from 2010 to 2040. Source: Urban Data Platform (European Commission, n.d.a).

European Union established CitySDK (software development kit), which is an applicable cross-domain smart city development programme that was issued by the Seventh Framework Programme (European Commission, n.d.b). Drawing on EU CitySDK, the US Census Bureau jointly with other agencies in the US federal government further established the CitySDK to make its authoritative data on the nation's people and economy as open data, which has a vision of making Census data more accessible to use and able to assist the policymakers and officers allocate their investments in a more reasonable way, 
business leaders optimise their operations and boost profits and so on (US Census Bureau, n.d.).

Apart from the smart tools developed by government, Google as a non-government stakeholder launched the Google Environmental Insights Explorer Beta in 2018(in Figure 3.), which employs the cartographic information in Google Maps to estimate carbon emissions and potential for solar power development etc. to facilitate the data collection and compile, as well as visualise SDGs in spatial manner and further point out the areas that require optimisation.

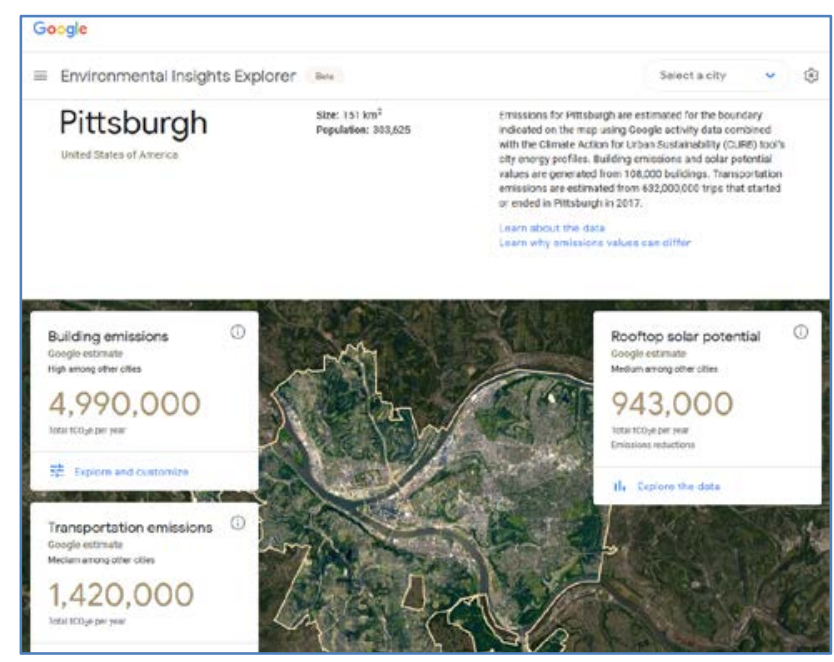

Figure 3. Building emissions, transport emissions and rooftop solar potential in Pittsburgh. Source: Google Environmental Insights Explorer (Google, 2017).

Above all, the employment of digital technologies as the smart tool, especially taking advantages of cartographic information, could greatly facilitate the sustainable development, since national government is able to understand the progress to achieve SDGs in a more intuitive approach and then make further strategic plans to promote and implement the SDGs more steadily towards shaping a smart and sustainable future.

\section{Towards sustainable future: Taiwan's efforts}

Looking back, Taiwan has been actively endeavouring to contribute to sustainable development. The National Council for Sustainable Development (NCSD), established by Taiwan's Executive Yuan in 1997, has completed a series of important documents, such as National Sustainable Development Policy Guidelines and Sustainable Development Action Plans, on sustainable development in Taiwan (Executive Yuan, 2017a). Moreover, Taiwan Govt. has also implemented several major national policies including Forward-looking Infrastructure Development Programme, Regional Revitalisation, the 5+2 Industrial Transformation Plan etc., which further facilitate the industrial transformation and promote the implementation of sustainable development goals.

In order to establish Taiwan's localised SDGs, the National Council for Sustainable Development (NCSD) held seven public fora in 2017 and 2018 to raise issues and concerns from public, focusing on six issues as priorities including smart water resources management, sustainable energy transformation, clean air, sustainable materials management and the circular economy, ecological conservation and green networks, as well as international partnerships for the SDGs (Lebada, 2018). Drawing on UN SDGs as well as taking into account the local circumstances, Taiwan drafted localised SDGs (in Table 3.), including 18 goals, 143 targets, and 342 indicators, beyond 17 UN SDGs is to establish a nuclear-free homeland by 2025 (Executive Yuan, 2017a).

\begin{tabular}{|c|c|}
\hline Item & Taiwan’s SDGs for 2030 \\
\hline 1 & $\begin{array}{l}\text { Strengthen social care services and economic } \\
\text { security for the disadvantaged }\end{array}$ \\
\hline 2 & $\begin{array}{l}\text { Ensure food security, eliminate hunger, and } \\
\text { advance sustainable agriculture }\end{array}$ \\
\hline 3 & $\begin{array}{l}\text { Ensure and promote healthy lives and wellbeing } \\
\text { for all at all ages }\end{array}$ \\
\hline 4 & $\begin{array}{l}\text { Ensure comprehensive, fair and high-quality } \\
\text { education, as well as advocate lifelong learning } \\
\text { opportunities for all }\end{array}$ \\
\hline 5 & $\begin{array}{l}\text { Achieve gender equality and empower all women } \\
\text { and girls }\end{array}$ \\
\hline 6 & $\begin{array}{l}\text { Ensure environmental quality and sustainable } \\
\text { management of environmental resources }\end{array}$ \\
\hline 7 & $\begin{array}{l}\text { Ensure access to affordable, reliable, sustainable } \\
\text { and modern energy for all }\end{array}$ \\
\hline 8 & $\begin{array}{l}\text { Promote sustained, inclusive and sustainable } \\
\text { economic growth, full and productive } \\
\text { employment, and decent work for all }\end{array}$ \\
\hline 9 & $\begin{array}{l}\text { Construct an affordable, safe, environment- } \\
\text { friendly, resilient, and sustainable transportation } \\
\text { infrastructure }\end{array}$ \\
\hline 10 & Reduce inequality within and among countries \\
\hline 11 & $\begin{array}{l}\text { Develop urban and rural areas that show } \\
\text { characteristics of fusion, safety, resilience, and } \\
\text { sustainability }\end{array}$ \\
\hline 12 & $\begin{array}{l}\text { Ensure sustainable consumption and production } \\
\text { patterns }\end{array}$ \\
\hline 13 & $\begin{array}{l}\text { Take urgent action to combat climate change and } \\
\text { its impacts }\end{array}$ \\
\hline 14 & $\begin{array}{l}\text { Conserve and sustainably use the oceans, seas and } \\
\text { marine resources, and prevent the ocean } \\
\text { environment from deteriorating }\end{array}$ \\
\hline 15 & $\begin{array}{l}\text { Conserve and sustainably use terrestrial } \\
\text { ecosystems to ensure the persistence of } \\
\text { biodiversity and the prevention of land } \\
\text { degradation }\end{array}$ \\
\hline 16 & $\begin{array}{l}\text { Promote a peaceful and diversified society. Ensure } \\
\text { judicial equality and build an accountable and } \\
\text { inclusive system }\end{array}$ \\
\hline 17 & $\begin{array}{l}\text { Establish diversified partnerships and work } \\
\text { together to advance the sustainable vision }\end{array}$ \\
\hline 18 & Establish a nuclear-free homeland by 2025 \\
\hline
\end{tabular}

Table 3. Taiwan’s SDGs. Source: Taiwan’s Voluntary National Review (Executive Yuan, 2017a). 
Furthermore, in progress to build the smart and sustainable society, Taiwan Govt. also has been actively exploring and harnessing digital technologies as the smart tool via R\&D to measure the SDGs progress as well as facilitate interactions among government, stakeholders, and individuals to further promote the policy implementations. GIS has been utilised to develop the National Geographic Information System (NGIS) and Community Geographic Information System (CGIS), forming the Decision Support System (DSS), to assist cross-domain and multiple stakeholders in cooperating in both top-down and bottom-up approaches.

\subsection{National Geographic Information System (NGIS): a top-down approach}

The inception and planning of developing the National Geographic Information System (NGIS) could date back to 1980 s, and the implementation began in 1998. Since then, the development of NGIS experienced several phases of improvement and optimisation to form 12 major databases and application-oriented team, which incorporate overground and underground features (topography, geology, hydrology, and land ownership) as well as attributes (text and symbolic), allowing users to overlap themed maps on the basis of their demands to obtain, process, and analyse the geospatial information (NGIS, n.d.).

Moreover, the themes of databases include natural environment, transportation network, and social economic etc., hence related government agencies could be aware of the current situation and conduct the fact-based decision making as well as release information to citizens via the system. For example, the natural environment database allows government agencies and citizens to understand the geology, rainfall, average temperature and other geospatial information (NGIS, n.d.).

In order to assess the SDGs progress by NGIS, National Council for Sustainable Development (NCSD) further makes the inventory for related data on the basis Taiwan's SDGs and assesses the reliability of the collected data, and then builds the analysis platform for SDGs data management and dashboard, as well as promotes the development and application of related SDGs data to the units that are responsible for data via the education and training approach.

In this process, a series of indices were used to evaluate the data, such as necessity, reliability, compatibility, accuracy, applicability, time efficiency etc., with the assistance of data science technologies such as geospatial data, data visualisation to further optimise the presentation and application of our national sustainability-related data, which could then be effectively compared with the database of United Nations.

In past years, NGIS has been successfully applied to improve public health in Taiwan. For instance, Tainan City employed "Geographic Information System for Dengue Prevention and Control" to search, track, monitor, and store the dengue-related geospatial data including weather conditions, community conditions, activity areas for the confirmed case, hidden disease sources, egg traps monitoring, which were then be analysed through big data technologies, allowing the Centres for Disease Control to promptly know the current situation, predict the possible future trend, and make effective prevention action plans (Tainan City Government, n.d.).

Moreover, Taiwan Govt. also effectively combines cross-domain themed maps for policy-making. Regarding SDG 3 Good Health and Well-being, facing the social issues of ageing society and increasing chronic diseases, the medical and welfare centres as well as multi-level clinics in Chiayi City has been investigated and visualised through NGIS, meanwhile the distribution and density of population over 65 in Chiayi are displayed in the same map (shown in Figure 4.) simultaneously. Such combination of two datasets could assist the policymakers in analysing whether or not the medical and welfare centres in Chiayi are enough to support all the ageing population and people with chronic or other diseases. Furthermore, the transport system map could also be overlapped on the map shown in Figure 4. to analyse whether or not the transport system is convenient enough for all elderly people and patients to access the proper healthcare institutes through the best commute approach. After the investigation and analysis, related government agencies could further make policies to optimise the structure of medical and welfare centres or the transport system to support all citizens, which will contribute to the SDG 3 - Leave No One Behind.

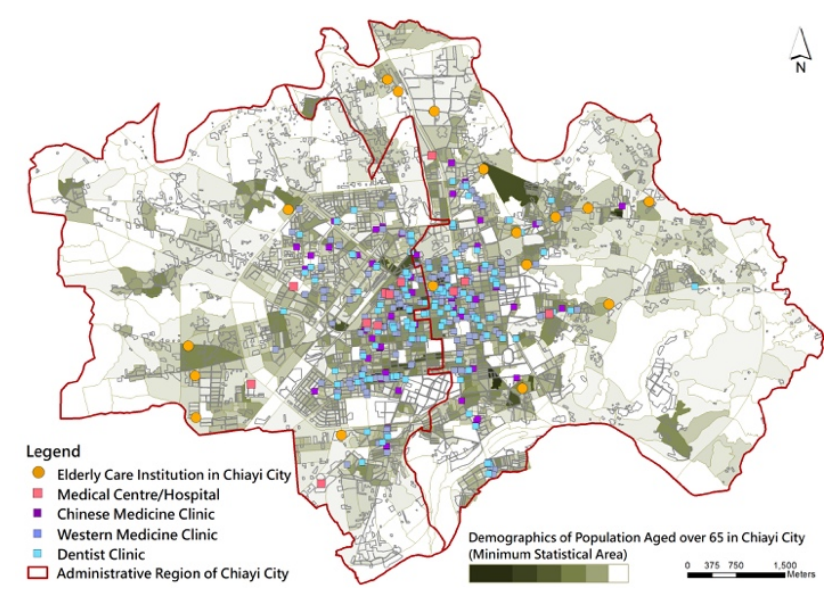

Figure 4. Dashboard of medical and welfare organisations in Chiayi. Figure source: Author; Data source: Ministry of Health and Welfare, NCSD, TGIC (internal).

Above all, Taiwan has been making significant efforts to strengthen the cross-sector cooperation and collaboration, draft the policy and plans to optimise and promote the entire NGIS, as well as improve the smart ability of NGIS to analyse and respond to problems, which will lay a solid foundation for achieving a smart and sustainable future for Taiwan.

\subsection{Community Geographic Information System (CGIS): a bottom-up approach}

Being developed for over 20 years, NGIS has accumulated rich fundamental data of geospatial information in national level; moreover, the application systems for diversified themes embedded in NGIS have been developed by related departments and councils based on the geospatial 
information, which has been gradually open to the public; furthermore, NGIS in city and town level are implemented in broader coverage.

However, the energy of NGIS is limited due to the information communication being hindered among different departments horizontally caused by inconsistent data integration, and the insufficient coverage and functions of the system in city and town level, as well as there is much room to improve in terms of the implementation of NGIS for localisation and realistic.

Under such circumstances and considering from the perspective of data users, the concept of Community Geographic Information System (CGIS) is proposed, where the town is regarded as the basic unit to build the platform and collect data, especially environmentalsensitive information and potential disaster information. The CGIS is expected to promote and facilitate the local authorities' work as well as assist disaster prevention and reduction during special times.

Unlike NGIS that functions in a top-down approach, CGIS takes a bottom-up approach to compile results from NGIS, which allows NGIS to realise its potential. Moreover, CGIS could promote public participation, which could further improve the management of local affairs and promote local development.

The establishment of CGIS relies on the overlaps of GIS layers from both geospatial perspectives (e.g., political or administrative boundaries, streets, land usage, and elevation) and time perspective (e.g., from the 1900s to 2000s) to record the local stories and revitalise the real world dynamically through GIS (shown in Figure 5.). Moreover, CGIS also allows local stakeholders and individuals to create and record their own stories in a particular time and spatial background.

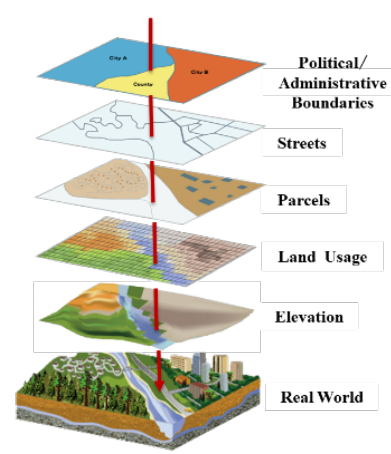

(a) Spatial relationship

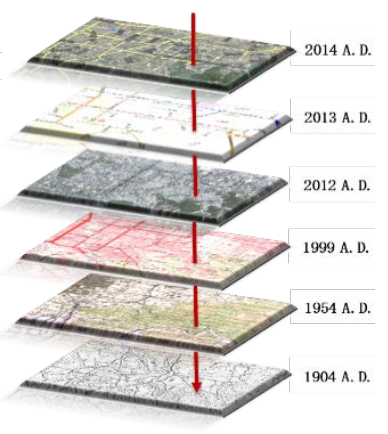

(b) Time relationship
Figure 5. Expanding the concept of GIS layers into the timespatial level. Source: Centre for GIS, RCHSS, Academia Sinica.

The concept of CGIS has been applied to develop smart tools and promote the national policies to address the issues Taiwan currently is facing, as well as build a smart and sustainable society.

Facing the challenges of ageing society, low birth rate and urban decay, many countries around the world are taking actions to address the issues. Among all, Japan applies the national strategy of Placemaking and developed the Regional Economy Society Analysing
System (RESAS) over GIS as a platform for people to access the information of the regional economy, allowing local areas to develop independently in a bottom-up approach instead of being governed by the central government (RESAS, n.d.). It encourages local schools to cultivate talents and conduct research to revitalise the local areas and attract talents to return by harnessing online framework and contemporary digital technologies.

Drawing on the experience of Japan, Taiwan started to promote the Regional Revitalisation Policy and set 2019 as the first year of Regional Revitalisation with the expectation to drive the population growth based on localised condition through the industrial development and technologies incorporation etc.; as a follow-up, National Development Council further developed the Taiwan Economic Society Analysis System (TESAS), based on GIS, to facilitate the local economy analysis in terms of population, economy and industry, medical and welfare, tourism etc. and further make policies and action plans (National Development Council, 2019).

Moreover, the model of CGIS could gather forces and consensus of local citizens and schools, as well as reproduce the memory of the public and provide the channel for professionals and web users to understand the local areas.

Hence, on the basis of GIS, both NGIS and CGIS could cooperate well to provide the comprehensive smart platform, which allows users to process and analyse the visualised data that contains geospatial information through different time from both top-down and bottom-up approaches to in an intuitive manner to facilitate the implementation of national policies towards shaping a smart and sustainable future.

\section{Data management}

Living in the smart and sustainable society, data is the fundamental unit that carries the information, which requires the massive data and open data to provide and transfer right information promptly; in turn, data is carried by the digital infrastructure, which requires robust infrastructure. Moreover, the smooth promotion and implementation of digital society could not function well without cyber security as the protection.

Firstly, open data could contribute significantly to better employment of digital technologies by providing more accessibility for people and more possibility for innovation and stimulating economic. United Nations launched the Open SDG Data Hub to promote the explorations, analysis, and application of SDG data as evidence for decision making, as well as make the global SDG indicators database easily accessed (United Nations, n.d.). The UK developed the Find Open Data for citizens to find data published by multiple stakeholders including central government, local authorities and public bodies to help stakeholders build products and services (GOV.UK, n.d.). Moreover, the UK made the key part of the Ordnance Survey (OS) MasterMap freely available, which is estimated to boost the economy by $£ 130 \mathrm{~m}$ a year (Ordnance Survey, 2018). Hence, effective employment of smart tools is the key to the promotion of sustainable 
development, meanwhile open data even locates at the core of shaping smart and sustainable country under the trend of digitisation.

However, the application of data faces challenges while making decisions based on overwhelm quantity of relevant and irrelevant data. Quote by Prof Yuval Noah Harari, the author of " 21 Lessons for the 21st Century" mentioned that "In a world deluged by irrelevant information, clarity is power. Censorship works not by blocking the flow of information, but rather by flooding people with disinformation and distractions. 21 Lessons for the 21st Century cuts through these muddy waters and confronts some of the most urgent questions on today's global agenda (Harari, 2018)". Nowadays, the explosive data and information could sometimes mislead policymakers to make the inappropriate judgement and decisions, hence policymakers should not only be able to interpret data but also harness the humanistic quality to assist them in identifying the right data and making good decisions.

However, data itself could not work without the platform to store, transfer, and manage data. Hence, many countries are making vast investments into digital infrastructure as the support. The UK has launched $£ 400$ million in Digital Infrastructure Investment Fund (DIIF) in 2017 with the expectation to revolutionise Britain's digital infrastructure, which is estimated to unlock $£ 1$ billion for full fibre broadband (GOV.UK, 2017). USA experts also highlighted the importance of digital infrastructure by suggestions that any new US project should be equipped with digital infrastructure (Descant, 2017). Taiwan Govt. also unveiled the plan to invest NT\$46 billion over eight years since 2017 to improve the digital infrastructure and bridge the gap between urban-rural areas (Executive Yuan, 2017b).

Furthermore, in recent years, countries around the world are facing the challenge arising from the environment of data application, especially the massive cyber-attack swept across the world in 2017 aroused people's awareness of data security again. As a response, European Commission launched General Data Protection Rule (GDPR) in 2018 to build stronger protection for personal and business data (European Commission, 2018), which could be helpful to ensure a secure environment for data users. Taiwan Govt. has set the goal - Cyber security is national security; hence, the Executive Yuan established the Department of Cyber Security in 2016, focusing on policy development of national information and communication security, cyberrelated task promotion etc. to fulfil the goal (NCCST, n.d.).

Above all, since data is the fundamental core in the digital age, the employment of GIS as a smart tool could be facilitated by the open data policy, investment and development of digital infrastructure, which contribute to the social and economic development. However, while taking advantages of data, people should be alert all the time to distinguish the "right" data from the massive database and ensure cyber security, so that data could function smoothly while implementing GIS in achieving sustainable development.

\section{Conclusion}

Facing severe challenges including climate change, rapid urbanisation, and digitisation in contemporary human society, many countries are endeavouring for sustainable development under the advocacy of United Nations with the 17 SDGs that was announced in 2015 meanwhile establish their localised and prioritised SDGs. Moreover, the development of digital technologies has provided unprecedented convenience for people's lives and save people from tremendous labour work as well as provided smart tools to facilitate the work.

Under such circumstances, Taiwan Govt. has been actively taking actions to achieve sustainable development, including the draft of Taiwan's 18 SDGs that not only draw on UN SDGs but also involve Taiwan's need for a sustainable future. In the process of endeavouring towards sustainable future, Taiwan Govt. also emphasises the significance of digital technologies by the development and promotion of NGIS-CGIS framework that allows both top-down and bottom-up approaches to further contribute to SDGs.

In order to further support the application of digital technologies as smart tools, it is important to provide open data for more people, develop robust and comprehensive digital infrastructure, and people should be equipped with the ability to distinguish the "right" data while facing controversial information conveyed by pure data, as well as the security of data management and employment should also be placed in the forefront to ensure the functioning of the smart tools.

In conclusion, with appropriate data management, GIS as a smart tool could contribute significantly to the promotion and implementation of SDGs towards shaping a smart and sustainable future.

\section{References}

Descant, S. (2017). Digital Infrastructure Should Be a Part of Any New U.S. Project, Experts Say. Retrieved from http://www.govtech.com/fs/infrastructure/DigitalInfrastructure-Should-Be-a-Part-of-Any-New-USProject-Experts-Say.html.

European Commission. (2018). 2018 reform of EU data protection rules. Retrieved from https:/ec.europa.eu/commission/priorities/justice-andfundamental-rights/data-protection/2018-reform-eudata-protection-rules_en.

European Commission. (n.d.a). Green Infrastructure per Capita. Retrieved from Urban Data Platform: https:/urban.jrc.ec.europa.eu/\#/europeantrends?level=CITY\&year=2050\&indicator=11_greenpe rcap\&type $=$ sdgs.

European Commission. (n.d.b). CitySDK. Retrieved from https://www.citysdk.eu/.

Eurostat. (n.d.). Sustainable Development Goals Overview. Retrieved from https://ec.europa.eu/eurostat/web/sdi.

Executive Yuan. (2017a). Taiwan's Voluntary National Review-Implementation of the UN Sustainable 
Development Goals. Retrieved from https://www.roctaiwan.org/uploads/sites/104/2017/09/Taiwan-VNR.pdf.

Executive Yuan. (2017b). Executive Yuan unveils digital infrastructure project. Retrieved from https://english.ey.gov.tw/News_Content2.aspx?n=8262 ED7A25916ABF\&sms=DD07AA2ECD4290A6\&s=1C C02A30D4D03E44.

Google. (2017). Building emissions, transport emissions and rooftop solar potential in Pittsburgh. Retrieved from Environmental Insights Explorer: https://insights.sustainability.google/.

Google. (n.d.). Environmental Insights Explorer. Retrieved from https://insights.sustainability.google/.

GOV.UK. (2017). Billion pound connectivity boost to make buffering a thing of the past. Retrieved from https://www.gov.uk/government/news/billion-poundconnectivity-boost-to-make-buffering-a-thing-of-thepast.

GOV.UK. (n.d.). Find open data. Retrieved from https://data.gov.uk/.

Harari, Y. (2018). 21 Lessons for the 21st Century. Retrieved from https://www.ynharari.com/book/21lessons/.

JRC, \& DG REGIO. (n.d.). Urban Data Platform. Retrieved from https://urban.jrc.ec.europa.eu/\#/about.

Lebada, A. (2018). Taiwan Launches 2018 SDG Progress Report. Retrieved from SDG Knowledge Hub: http://sdg.iisd.org/news/taiwan-launches-2018-sdgprogress-report/.

Miao, J. T., Chen, C. W., \& Phelps, N. A. (2018). On the way to smartness: what, why and how (in Mandarin). Retrieved from https://ngis.nat.gov.tw/ngis2/PeriodicalDetail02.aspx.

National Development Council. (2019). National Strategic Programme of Regional Revitalisation. Retrieved from https://ws.ndc.gov.tw/Download.ashx?u=LzAwMS9hZ G1pbmlzdHJhdG9yLzEwL3JlbGZpbGUvMC8xMTUw MC85ZDc5OTk1OS1jMmRkLTQ2NDEtOWQ3Mi1m ZjIyYzI1ZjBlMTMucGRm\&n=5Zyw5pa55Ym155Sf5Z yL5a625oiw55Wl6KiI55Wr57Ch5aCxKOihjOaUv\%2b mZojEwODAxMDPmoLjlrprniYgpdjEo5L\%2buKSgg5 rWu5rC05Y2wKS5wZGY\%3d\&icon=..pdf.

NCCST. (n.d.). National Centre for Cyber Security Technology.https://www.nccst.nat.gov.tw/Default?lang =en

NGIS. (n.d.). National Geographic Information System. Retrieved from: https://ngis.nat.gov.tw/ngis2/.

Ordnance Survey. (2018). Unlocking of Government's mapping and location data to boost economy by $£ 130 \mathrm{~m}$ a year. Retrieved from https://www.ordnancesurvey.co.uk/about/news/2018/ma stermap-announcement.html.

RESAS. (n.d.). Regional Economy Society Analysing System. Retrieved from: https://resas.go.jp/\#/13/13101
SDGs Promotion Headquarters. (2016). The SDGs Implementation Guiding Principles. Japan. Retrieved from: https://www.mofa.go.jp/files/000252819.pdf.

SDGs Promotion Headquarters. (2017). Japan's Voluntary National Review-Report on the implementation of the Sustainable Development Goals. Retrieved from https://sustainabledevelopment.un.org/content/document s/16445Japan.pdf.

SDSN. (2018). SDG Index and Dashboards Report 2018. Retrieved from https://dashboards.sdgindex.org/\#/.

SDSN, \& German Cooperation. (2016). Getting Started with the SDGs in Cities. Retrieved from http://unsdsn.org/wp-content/uploads/2016/07/9.1.8.Cities-SDG-Guide.pdf.

Taiwan City Government. (n.d.). Geographic Information System for Dengue Prevention and Control. Retrieved from http://dengue.tainan.gov.tw/.

UK Github. (n.d.). UK data for Sustainable Development Goal indicators. Retrieved from https://sustainabledevelopment-uk.github.io/.

United Nations. (2016). Switzerland Voluntary National Review 2016. Retrieved from Sustainable Development Goals Knowledge Platform: https://sustainabledevelopment.un.org/memberstates/swi tzerland.

United Nations. (2017). Resolution adopted by the General Assembly on 6 July 2017. Retrieved from https://undocs.org/A/RES/71/313.

United Nations. (2018a). Switzerland Voluntary National Review 2018. Retrieved from Sustainable Development Goals Knowledge Platform: https://sustainabledevelopment.un.org/memberstates/swi tzerland.

United Nations. (2018b). Singapore Voluntary National Review 2018. Retrieved from Sustainable Development Knowledge Platform: https://sustainabledevelopment.un.org/memberstates/sin gapore.

United Nations. (2018c). E-Government Survey 2018. Retrieved from https://publicadministration.un.org/egovkb/Portals/egov kb/Documents/un/2018-Survey/E-

Government\%20Survey\%202018_FINAL\%20for\%20w eb.pdf.

United Nations. (n.d.). Open SDG Data Hub. Retrieved from https://unstats-undesa.opendata.arcgis.com/.

US Census Bureau. (n.d.). CitySDK. Retrieved from https://uscensusbureau.github.io/citysdk/.

US Govt. (n.d.). U.S. National Statistics for the UN Sustainable Development Goals. Retrieved from https://sdg.data.gov/statistics/.

World Economic Forum. (2019). Globalisation 4.0 Shaping a new global architecture in the age of the fourth industrial revolution (White Paper). Retrieved from http://www3.weforum.org/docs/WEF_Globalization_4. 0_Call_for_Engagement.pdf. 